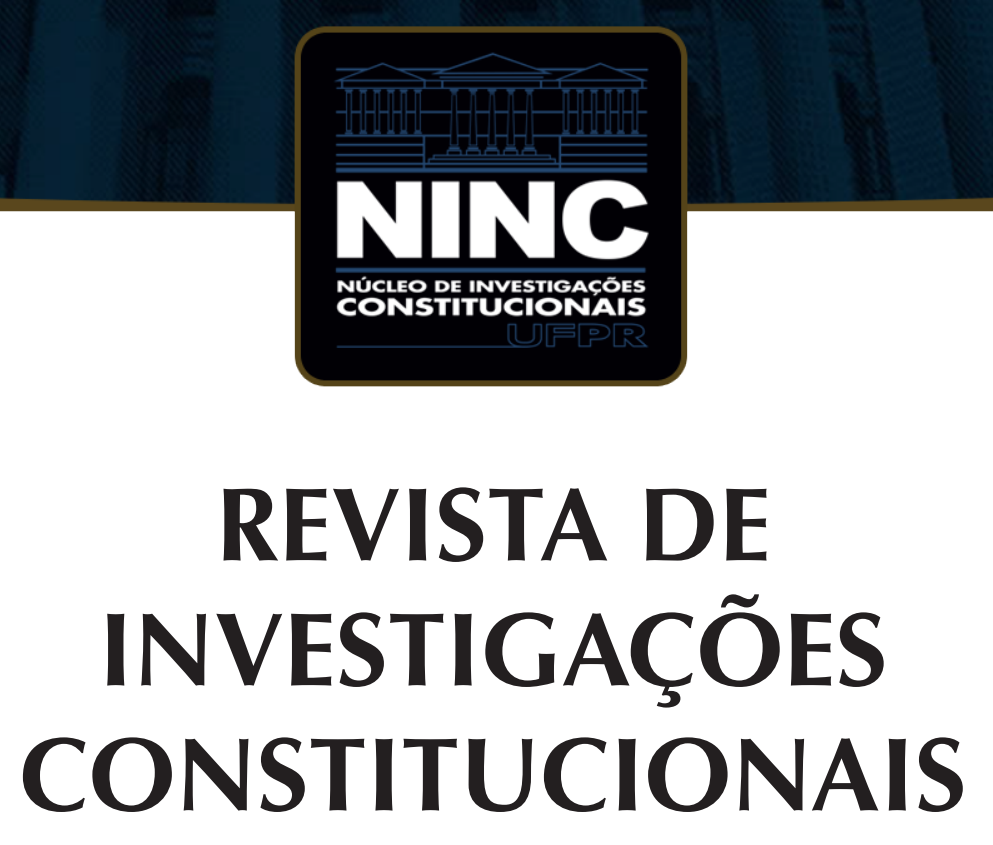

JOURNAL OF CONSTITUTIONAL RESEARCH

vol. 8 | n. 1 | janeiro/abril 2021 | ISSN 2359-5639 | Periodicidade quadrimestral Curitiba | Núcleo de Investigações Constitucionais da UFPR | www.ninc.com.br 


\title{
Desintegração jurídica e uma teoria do Estado*
}

\section{Legal Disintegration and a Theory of the State}

\author{
WILLIAM H. CLUNE ${ }^{\text {,*** }}$ \\ ' University of Wisconsin (Madison, Estados Unidos da América) \\ whclune@wisc.edu \\ https://orcid.org/0000-0002-4160-8632 \\ Recebido/Received: 28.11 .2020 / November $28^{\text {th }}, 2020$ \\ Aprovado/Approved: 17.02.2021 / February $17^{\text {th }}, 2021$
}

\section{Resumo}

Este artigo descreve uma topologia do pensamento jurídico e as condições sociais de que essa topologia, esse pensamento, é um componente. Propõe-se que o pensamento jurídico seja composto por um núcleo e uma periferia e que toda a estrutura corresponda aproximadamente à dicotômica e fragmentada economia política do moderno Estado de bem-estar social democrático. A parte I é uma descrição da estrutura do pensamento jurídico. Nesse sentido, considera-se que o pensamento jurídico possui um núcleo e uma periferia, ambos os quais interagem de maneiras que denomino transição e reintegração. O núcleo compreende um modelo de Tribunais, litigância e processos judiciais; um modelo de

\section{Abstract}

This paper describes a topology of legal thought and the social conditions of which that topology is a component. It is proposed that legal thought is composed of a core and periphery and that the whole structure roughly corresponds to the dichotomous and fragmented political economy of the modern democratic welfare state. Part I is a description of the structure of legal thought. In this sense, legal thought is considered to have a core and a periphery, both of which interact in ways that I call transition and reintegration. The core comprises a model of courts, litigation and cases; a private law model of social order; ethical justification; interpretive reasoning; and a hegemonic view of legal influence. The periphery, in its turn, is composed of legislation and

Como citar esse artigo/How to cite this article: CLUNE, William H. Desintegração jurídica e uma teoria do Estado. Revista de Investigações Constitucionais, Curitiba, vol. 8, n. 1, p. 107-133, jan./abr. 2021. DOI: 10.5380/rinc.v8i1.82326.

* N.T. 1) A versão original deste artigo em inglês foi publicada em TRUBEK, D.; JOERGES, C. (Orgs.). Critical Legal Thought: An American-German Debate. Baden-Baden: Nomos, 1989, e posteriormente republicada em CLUNE, William H., Legal Disintegration and a Theory of the State, German Law Journal, v. 12, n. 1, p. 186-205, 2011. A tradução se baseia nesse último. 2) O texto original usa linguagem coloquial e, em diversas passagens, primeira pessoa, diferentemente do padrão corrente em artigos acadêmicos. Além disso, contém redundâncias, advérbios e construções linguísticas de difícil compreensão quando traduzidas, o que levou, em certas passagens, à opção pela sua simplificação. 3) Quando o termo Direito se refere ao campo do conhecimento, optou-se por letras maiúsculas, para facilitar a identificação, o que foi utilizada para a identificação de disciplinas, como Direito Ambiental, Direito Falimentar etc., com minúsculas no original. 4) Tradução para o português feita por Bruno Bodart e Sergio Ruy David Polimeno Valente, com revisão técnica de Maria Paula Dallari Bucci.

** Professor Emérito da Faculdade de Direito da Universidade de Wisconsin (Madison, Estados Unidos). Diretor do Grupo de Política do Instituto Nacional para Educação Científica e pesquisador sênior do Consórcio para Pesquisa Política em Educação (CPRE). J.D. - Juris Doctor, Northwestern Law School. Email: whclune@wisc.edu. 
Direito Provado da ordem social; justificação ética; racionalidade interpretativa; e uma visão hegemônica da influência jurídica. A periferia, por sua vez, é composta pela legislação e diplomas; um modelo de Direito Público da ordem social; análise de política pública como racionalidade; interpretação jurídica positivista; e uma visão marginalista da influência jurídica. A parte II descreve a estrutura do Direito e a sua relação com a Economia política, incluindo as tendências em direção à reintegração nos aspectos periféricos da Economia política, enfatizando a cooperação social. A conclusão considera o lugar da prática jurídica tradicional em um novo panorama.

Palavras-chave: Filosofia do Direito; pensamento jurídico; teoria jurídica crítica; Economia Política; Teoria do Estado. statutes; a public law model of social order; policy analysis as justification; positivist legal interpretation; and a marginalist view of legal influence. Part II describes structure of law and its relation to political economy, including tendencies toward reintegration in the peripheral aspects of political economy emphasizing social cooperation. The Conclusion considers the place of traditional legal practice on a new landscape.

Keywords: Jurisprudence; legal thought; critical legal theory; Political Economy; Theory of State.

\section{SUMÁRIO}

1. Introdução; 2. Um modelo básico de pensamento jurídico: núcleo, periferia, transição e além; 2.1. As cinco dimensões do pensamento jurídico; 2.2. Descrições de cada dimensão, formas transitórias e reintegrativas; $\mathbf{2 . 3}$. Um resumo: a dinâmica do núcleo e da periferia; 2.4. Um pequeno estudo de caso: Direito da responsabilidade civil (tort law) por ato ilícito em transição; 3. Desintegração no pensamento jurídico e na teoria do Estado; 3.1. Os dois projetos do capitalismo: liberdade econômica e interdependência social; 3.2. Impacto dos dois projetos sobre o Direito: efeitos separados; 3.2.1. O núcleo da liberdade econômica; 3.2.2. A periferia da interdependência social; 3.3. Impacto das contradições no Direito; 3.3.1. Questões de acesso a benefícios coletivos; 3.3.2. O desenho do Estado de bem-estar social; 3.3.3. Democracia liberal; 4. Conclusão: o Direito tradicional em uma nova chave, caminhos antigos em um novo cenário; 5 . Referências.

\section{INTRODUÇÃO}

Este artigo descreve uma topologia do pensamento jurídico e as condições sociais (uma construção social mais ampla da realidade) de que essa topologia, esse pensamento, é um componente. A parte I é uma descrição da estrutura do pensamento jurídico; a parte II, das condições sociais (uma teoria do estado, ou economia política). A conclusão considera o lugar da prática jurídica tradicional em um novo cenário.

Percebe-se o pensamento jurídico, grosso modo, como uma progressão desde o primeiro ano do curso de direito, com ênfase na common law e no método jurídico, passando pelo segundo e terceiro anos, sobre direito positivo (statutory law) e regulamentação da economia, até experiências posteriores de sociologia do direito, análise de políticas e pensamento crítico. Consequentemente, em sua totalidade, o pensamento jurídico poderia ser representado pelo currículo e pesquisa de qualquer faculdade de direito moderna grande e sofisticada, como a minha. Mas o pensamento jurídico 
é maior do que a academia (moldando inúmeros atos jurídicos oficiais: casos, textos normativos, debates etc.) e diferente da prática jurídica (cuja relação com o pensamento jurídico não é clara). ${ }^{1}$

Propõe-se que o pensamento jurídico seja composto por um núcleo e uma periferia e que toda a estrutura corresponda aproximadamente à dicotômica e fragmentada economia política do moderno Estado de bem-estar social democrático. Assim, o movimento deste artigo parte da fenomenologia jurídica (a experiência do pensamento jurídico) para um tipo correspondente de organização cultural, chamada economia política. $^{2}$

O problema que se tenta enfrentar é um sentido concomitante de desintegração e integração (ou movimento progressivo) no direito. Após um período inicial de paixão pelo seu poder conceitual e elegância, o observador do pensamento jurídico começa a ver fragmentação, uma variedade de epistemologias, filosofias sociais e instrumentos de política, cheios de conflitos, retalhos desleixados e lacunas, ou descontinuidades desorientadoras. Ao mesmo tempo, parece haver uma estrutura para a desordem (embora fragmentado, o direito não é uma pilha caótica de escombros) e um movimento progressivo em direção à resolução eficiente de problemas sociais. Neste artigo, gostaria de esclarecer este sentido de desordem ordenada e progresso, maculados a cada passo do caminho por conflitos e confusão. Ao olhar primeiro para dentro do pensamento jurídico, depois para fora do seu contexto cultural mais amplo, espero evitar o idealismo árido ou o conceptualismo e alcançar um tipo de energia e profundidade de explicação que de outra forma não seriam possíveis. (Também rejeito implicitamente uma interpretação do pensamento jurídico como exclusivamente um produto ideológico da academia jurídica. ${ }^{3}$ Considero o pensamento jurídico como, pelo menos em parte, um produto de uma construção maior da realidade, de fato de toda a sociedade).

Embora os advogados possam fazer seus trabalhos pragmáticos com pouca ideologia formal, ao longo do artigo entendo que, conscientemente ou não, tipos de prática podem ser identificados com projetos característicos de pensamento jurídico. Ver também a Conclusão.

2 Embora a economia política lide com coisas materiais, considero que é essencialmente cultural, um aspecto da consciência, porque é fundamentalmente um conjunto estável de autorreprodução de expectativas mútuas sobre coisas materiais. A economia política parece mais distante e objetiva (e certamente, em certo sentido, além da periferia do pensamento jurídico); mas também fazemos parte da economia política e, portanto, podemos experimentá-la fenomenologicamente. Ver abaixo, nota 19.

3 SCHLEGEL, John H. American Legal Theory and American Legal Education: A Snake Swallowing its Tail? In: TRUBEK, D.; JOERGES, C. (Orgs.). Critical Legal Thought: An American-German Debate. Baden-Baden: Nomos, 1989. p. 49-84. Concordo com Schlegel que o pensamento jurídico ajuda os acadêmicos do direito a se diferenciarem tanto da prática jurídica quanto dos departamentos acadêmicos, mas também vejo conexões com padrões mais amplos de pensamento social. 


\section{UM MODELO BÁSICO DE PENSAMENTO JURÍDICO: NÚCLEO, PE- RIFERIA, TRANSIÇÃO E ALÉM}

O esquema básico do pensamento jurídico apresentado na Parte I é o seguinte: o pensamento jurídico tem um núcleo de "direito tradicional", consistindo em um modelo de tribunais, litígios e casos; um modelo de ordem social de direito privado; justificativa ética; raciocínio interpretativo; e uma visão hegemônica da influência jurídica. A periferia do pensamento jurídico é composta pelos opostos dos elementos do núcleo: legislação e textos normativos; um modelo de ordem social de direito público; análise de políticas como justificativa; interpretação jurídica positivista; e uma visão marginalista da influência jurídica. ${ }^{4}$

Como os elementos do núcleo e da periferia são construídos como opostos, o espaço conceitual entre eles é vazio ou descontínuo; e o pensador jurídico sente-se puxado em direções opostas, alternando entre os dois sem uma transição adequada. O movimento do núcleo para a periferia é influenciado por poderosas forças opostas, como forças centrípetas e centrífugas. No núcleo, o direito parece natural, seguro (sem contestação), inalterado por paradigmas ou racionalidades incompatíveis.

O núcleo também é um espaço com uma atraente mistura de raciocínio moral e filosofia social. Na periferia, tudo é oposto: o direito parece estranho, burocrático e desafiado tanto por outras formas de pensamento quanto por outros tipos de especialistas. Nesse sentido, existe uma poderosa força centrípeta que impulsiona o pensamento jurídico para suas instituições centrais. Mas também há uma força intensa correndo na direção oposta. No núcleo, o direito parece abstrato, socialmente inconsequente, obsoleto; enquanto na periferia parece moderno, relevante, substantivo, poderoso.

Núcleo e periferia já seriam complicados o suficiente, mas há outra coisa. Deixe-me chamá-la de "transição" e "reintegração": um esforço para projetar valores do núcleo na periferia, quebrando o espaço descontínuo entre eles; e, no processo, estendendo o escopo do pensamento jurídico para algo que parece "além do direito". ${ }^{5}$ Atributos positivos do núcleo, como raciocínio moral e filosofia social, estão sendo combinados com elementos positivos da periferia, como sofisticada resolução de problemas sociais. A transição consiste em simples híbridos de núcleo e periferia (que podem ser representados como localizados no espaço descontínuo entre os dois). A reintegração ocorre quando a estrutura do núcleo e da periferia se quebra e algo é criado além do

4 A ideia de núcleo e periferia obviamente deve muito a Duncan Kennedy: KENNEDY, Duncan. The political significance of the structure of the law school curriculum. Seton Hall Law Review, Newark, v. 14, n. 1, pp. 1-16, 1983; KENNEDY, Duncan. Form and Substance in Private Law Adjudication. Harvard Law Review, Cambridge, v. 89, n. 8, pp. 1685-1778, 1976. Este artigo difere da concepção de Kennedy em vários aspectos, por exemplo: incorporando a análise de políticas (e a tese da rematerialização em geral); vendo um movimento progressivo do núcleo para a periferia; e vendo o capitalismo como implicado na construção do núcleo e da periferia e nas contradições entre eles e dentro deles.

5 Ver seção B.Il.2, infra. 
direito. Incompatibilidades entre núcleo, periferia, transição e reintegração emprestam um senso de contradição e confusão a toda a estrutura ou topologia do pensamento jurídico.

\subsection{As cinco dimensões do pensamento jurídico}

Núcleo, periferia, transição e reintegração podem ser retratados em cinco dimensões, como segue. (As seções subsequentes descreverão as dimensões com mais detalhes). ${ }^{6}$

Dimensão: arena (agency) de tomada de decisão, processo e tipo de decisão

Núcleo: tribunais, litígios, caso concreto

Periferia: legislativos, legislação, textos normativos

Transição: litígio de direito público, direitos legais de ação

Reintegração: legislação sobre problemas sociais, direitos constitucionais de bem-estar social

Dimensão: substância da decisão

Núcleo: direito privado

Periferia: direito público

Transição: regulação judicial, common law como economicamente racional

Reintegração: lei reflexiva (organizações intermediárias de política)

Dimensão: tipo de justificação ou racionalização

Núcleo: análise jurídica

Periferia: análise de políticas públicas

Transição: direito e economia (Law and Economics)

Reintegração: considerações morais na política de bem-estar social, análise de políticas como participação e empoderamento

Dimensão: tipo de interpretação

Núcleo: raciocínio moral

Periferia: raciocínio positivo

Transição: teleologia da lei (statutory intent)

Reintegração: interpretação situacional das leis, etc.

6 As dimensões correspondem um pouco ao que os europeus na tradição weberiana chamam de "rematerialização" do direito. TEUBNER, Gunther. Substantive and Reflexive Elements in Modern Law. Law \& Society Review, New Jersey, v. 17, n. 2, pp. 239-286, 1983. 
Dimensão: papel do direito

Núcleo: hegemônico

Periferia: marginal

Transição: implementação

Reintegração: escolha institucional

\subsection{Descrições de cada dimensão, formas transitórias e reintegrati- vas}

Esta seção do artigo oferece uma descrição de cada dimensão do pensamento jurídico, elaborando melhor a apresentação esquemática da seção anterior.

Tribunais, contencioso, caso concreto/legislativos, legislação, textos normativos. No núcleo, a ação jurídica ocorre nos casos concretos, por meio de tribunais e litígios. O direito é resolução de disputas; a mudança é uma piada. Na periferia, os legislativos fazem legislação social abrangendo áreas de problemas sociais, em vez de situações individuais. As formas transitórias incluem litígios de direito público (onde o remédio rompe com a disputa subjacente e aborda uma área de problemas sociais) e direitos de ação privados previstos em lei (onde se imagina que a lei crie uma zona de proteção para indivíduos). Não consigo pensar em nenhuma forma verdadeiramente reintegrativa. Seria como abrir um processo judicial para resolver um problema social. O contencioso da reforma social se aproxima dessa noção, assim como a idéia de Michelman de benefícios de bem-estar constitucionalmente exigidos.?

Direito privado / direito público. No núcleo, o direito assume a forma de relações jurídicas entre indivíduos, ou seja, em geral, a forma de direitos (propriedade, responsabilidade civil por ato ilícito, direito penal). Na periferia, assume a forma de planejamento social, ou engenharia, com foco nas consequências e comportamentos de organizações, grupos, setores e sociedades. As formas transitórias incluem a proliferação de considerações de direito público na elaboração do direito privado (por exemplo, interesse público invadindo o direito de propriedade supostamente absoluto, regulação judicial dos contratos). ${ }^{8}$ Outra instituição de transição é a sugestão, de direito e economia, de que o direito privado sirva automaticamente para fins públicos, ajustando-se às imperfeições do mercado. Uma reintegração é a ideia contemporânea de usar organizações

\footnotetext{
MICHELMAN, Frank I. On Protecting the Poor Through the Fourteenth Amendment. Harvard Law Review, Cambridge, v. 1, n. 1, pp. 6-59, 1969; MICHELMAN, Frank I. In Pursuit of Constitutional Welfare Rights: One View of Rawls'Theory of Justice. University of Pennsylvania Law Review, Pennsylvania, v. 121, n. 5, pp. 962-1019, 1973.

8 KENNEDY, Duncan. Distributive and Paternalist Motives in Contract and Tort Law, with Special Reference to Compulsory Terms and Unequal Bargaining Power. Maryland Law Review, v. 41, n. 4, pp. 563-658, 1982.
} 
intermediárias como veículos para políticas sociais (por exemplo, planos de saúde) ${ }^{9 *}$, escolas, empresas de opinião pública e casas de repouso). Esse "direito reflexivo" tenta combinar engenharia social com um senso de voluntarismo e direitos individuais. ${ }^{10}$

Análise jurídica / análise de políticas. O raciocínio jurídico é conceitual, ético, analógico; e repousa (um tanto paradoxalmente) em uma visão ética do mundo, uma imagem de uma sociedade justa e ordenada. A análise de políticas é consequencialista (apoiando-se em previsões sobre comportamento social, incluindo tudo, desde desvio social a orçamentos equilibrados). A análise de políticas é substancialmente específica, exigindo conhecimento especializado sobre os comportamentos de sistemas sociais específicos, como educação, bancos e polícia. Portanto, na periferia, a análise jurídica é fortemente contestada por conhecimentos substantivos, tanto gerais (economia, análise de políticas) quanto especiais (por exemplo, conhecimento técnico sobre poluição). A análise de políticas também tende a ser substancialmente fragmentada e ad hoc, uma série de soluções para problemas sociais específicos. Direito e economia é uma forma de transição clássica, tentando investir o raciocínio jurídico com potência consequencialista. Uma poderosa forma reintegrativa está apenas emergindo: a ideia do Estado de bem-estar social como incorporando uma série de julgamentos morais sobre a sociedade. ${ }^{11}$ Outra reintegração é uma nova forma de análise de políticas onde a ênfase está na participação e no empoderamento, e não na implantação tipo comando-controle, de cima para baixo (top-down). ${ }^{12}$

Raciocínio Jurídico / Raciocínio Positivista. Aqui passamos do raciocínio sobre a formação do direito (justificativa para elaborar o direito) para a interpretação do direito (o significado do direito já elaborado). O raciocínio jurídico no núcleo (common law) combina justificação e interpretação em um único ato. O raciocínio jurídico na periferia é positivista, tratando as decisões como já tomadas (por exemplo, nas disposições específicas dos textos normativos) e um grande número de decisões em rotinas burocráticas

\footnotetext{
$9 \quad$ *NT. No original, HMO, que deve se referir a Health Maintenance Organization.

10 TEUBNER, Gunther. Substantive and Reflexive Elements in Modern Law. Law \& Society Review, New Jersey, v. 17, n. 2, pp. 239-286, 1983.

11 PIORE, Michael; SABEL, Charles. The Second Industrial Divide: Possibilities for Prosperity. New York: Basic Books, 1984; SIMON, William H. Rights and Redistribution in the Welfare System. Stanford Law Review, Stanford, v. 38, n. 6, pp. 1431-1516, 1986.

12 HANDLER, Joel F. The Conditions of Discretion. [s.I.]: Russell Sage Foundation, 1986; BARDACH, Eugene; KAGAN, Robert A. Going by the Book: The Problem of Regulatory Unreasonableness. Philadelphia: Temple University Press, 1982; TAYLOR, Serge. Making Bureaucracies Think: The Environmental Impact Statement Strategy of Administrative Reform. Stanford: Stanford University Press, 1984. A aplicação mais pura da abordagem está no gerenciamento de negócios: PETERS, Thomas J.; JR., Robert H. Waterman. In search of excellence: Lessons from America's best-run companies. New York: Harper \& Row, 1982; KANTER, Rosabeth M. The Change Masters - Innovation and Entrepreneurship in the American Corporation. New York: Simon Schuster, 1984.
} 
(por exemplo, os procedimentos operacionais padrão da administração da previdência social). A teleologia (statutory intent) é uma forma de transição (por exemplo, interpretação dos textos normativos com base em objetivos de política). A reintegração é desenfreada, incluindo interpretação pura como um cânone da interpretação jurídica ${ }^{13}$, interpretação situacional da lei à luz da aplicação local, ${ }^{14}$ e o interpretativismo universal da linha dos Critical Legal Studies - CLS (aplicado a casos, leis e análise de políticas). ${ }^{15}$

Direito hegemônico / Direito socialmente marginal. No núcleo, não há distinção entre direito e conformidade (as regras são discutidas como se as pessoas as cumprissem). Graças principalmente à sociologia do direito, o pensamento jurídico periférico agora aceita a idéia da marginalidade do direito na sociedade. Os comandos legais são reconhecidos como mediados por campos privados de incentivos e valores, com vários resultados (pouco ou nenhum efeito, efeito reduzido, efeitos não intencionais, etc.). $A$ indeterminação de efeitos criou problemas para a análise jurídica e, devido à frequente disjunção entre objetivos morais e resultados comportamentais, forçou a análise jurídica na direção da análise política consequencialista. As formas transitórias incluem a análise da implementação, que procura especificar o impacto preciso dos programas jurídicos. ${ }^{16}$ Mas a implementação, como o núcleo do direito hegemônico, mantém uma visão da sociedade centrada no Estado. A reintegração inclui teorias de escolha institucional, como economia de custos de transação. ${ }^{17}$ (As opções para regular transações incluem mercados, hierarquias, trust ${ }^{18^{*}}$ e, em certas situações especializadas,

13 CALABRESI, Guido. A Common Law for the Age of Statutes. Cambridge: Harvard University Press, 1982; POSNER, Richard. Statutory Interpretation in the Classroom and in the Courtroom. University of Chicago Law Review, Chicago, v. 50, pp. 800-822, 1983; MASHAW, Jerry L. Positive Theory and Public Law. In: Rosenthal Lectures. [s.l.]: palestra proferida na Northwestern University Law School, arquivo do autor, fev. 1986.

14 BARDACH, Eugene; BARDACH, Eugene; KAGAN, Robert A. Going by the Book: The Problem of Regulatory Unreasonableness. Philadelphia: Temple University Press, 1982.

15 BOYLE, James. The Politics of Reason: Critical Legal Theory and Local Social Thought. University of Pennsylvania Law Review, Pennsylvania, v. 133, n. 4, pp. 685-780, 1985. p. 685; PELLER, Gary; ACKERMAN, Bruce. The Politics of Reconstruction. Harvard Law Review, Cambridge, v. 98, n. 4, pp. 863-881, 1985.

16 Em certo sentido, meu próprio trabalho sobre implementação tem se preocupado em sintetizar descobertas da sociologia do direito sobre campos sociais privados com descobertas da implementação sobre a variabilidade local de impacto. Integrei as duas perspectivas em uma estrutura de ação política, reação e construção social em todas as etapas do processo de implementação: CLUNE, William H. A Political Model of Implementation and Implications of the Model for Public Policy, Research, and the Changing Roles of Law and Lawyers. lowa Law Review, lowa City, v. 69, pp. 47-125, 1983; CLUNE, William H.; PELT, Mark H. Van. A Political Method of Evaluating the Education for All Handicapped Children Act of 1975 and the Several Gaps of Gap Analysis. Law and Contemporary Problems, Durham, v. 48, n. 1, pp. 7-62, dec./feb. 1985.

17 PALAY, Thomas M. Comparative Institutional Economics: The Governance of Rail Freight Contracting. The Journal of Legal Studies, Chicago, v. 13, n. 2, pp. 265-287, 1984; KOMESAR, Neil K. Taking Institutions Seriously: Introduction to a Strategy for Constitutional Analysis. The University of Chicago Law Review, Chicago, v. 51, n. 2, pp. 366-446, 1984; CLUNE, William H. Institutional Choice as a Theoretical Framework for Research on Educational Policy. Educational Evaluation and Policy Analysis, [s.I.], v. 9, n. 2, pp. 117-132, jun. 1987.

18 *N.T. Aparentemente, se refere a "trust" enquanto instituto, não "confiança". 
tribunais). Por uma reconceptualização de tirar o fôlego, o objetivo jurídico é definido como escolher entre instituições, jurídicas e não-jurídicas, anexando assim o território anteriormente não-jurídico e relegando o território anteriormente jurídico ao status marginal (por exemplo, disputas judiciais sobre capital idiossincrático entre estranhos ou pessoas que terminam um relacionamento).

\subsection{Um resumo: a dinâmica do núcleo e da periferia}

O efeito cumulativo de todas essas dimensões é um dinamismo energizado entre o núcleo e a periferia do pensamento jurídico. Um dos efeitos são a introspecção e uma mentalidade provincial, à medida que os profissionais do direito se apegam ansiosamente aos símbolos e atividades principais de sua especialidade, interpretação jurídica e litígios, mesmo à custa da obsolescência gradual. (A ação de retaguarda dos advogados que defendem o sistema de responsabilização civil por ato ilícito em ruínas é um exemplo, juntamente com a indiferença um tanto chocante dos profissionais do direito em pensar nos sistemas de compensação de uma maneira mais sistemática. Veja a próxima seção).

Mas exatamente a tendência oposta ocorre ao mesmo tempo, uma torrente de novas perspectivas, atividades e instituições, a ponto de o discurso de uma faculdade de direito privilegiada e progressista se tornar extremamente heterogêneo, uma espécie Nações Unidas do campo intelectual. Profissionais jurídicos sabem muito sobre diferentes tipos de instituições - departamentos de polícia, empresas, famílias, escolas, agricultura, mulheres, produção de energia nuclear, repartição de água escassa, tratados fiscais internacionais, leis em sociedades socialistas, sistemas de saúde, contratos de entretenimento e esportivos, hábitos de compra do consumidor, publicidade na TV para crianças, sindicatos, manutenção de renda para os pobres, assistência médica para esquizofrênicos sem-teto e as necessidades de asilo dos refugiados salvadorenhos (sem sequer tocar nas diversas formas teóricas, disciplinares e etnográficas de experimentar esses fenômenos).

O direito é uma pequena fortaleza que oferece uma perspectiva restrita e artificial do mundo exterior através de suas escotilhas estreitas de método e procedimentos legais; mas as portas da fortaleza estão escancaradas; e o forte está cheio de diferentes estranhos todos os dias. A dicotomização do direito é, portanto, um fenômeno dinâmico que consiste em pressão interna no ponto de vista exclusivamente jurídico e pressão externa na intrusão de perspectivas exteriores. A sensação total é energética e desconfortável. 


\subsection{Um pequeno estudo de caso: Direito da responsabilidade civil (tort law) por ato ilícito em transição}

Neste ponto, um exemplo concreto das tendências acima provavelmente seria útil. $\mathrm{O}$ exemplo do direito de responsabilidade civil por ato ilícito em transição reflete muitas das tendências e também fornece uma introdução em alguma medida para a Parte $\mathrm{B}^{19}$. A transição é tanto topológica (movendo-se de locais diferentes em um mapa existente do pensamento jurídico) quanto, penso, histórica (pelo menos nas linhas gerais).

O direito da responsabilidade civil por ato ilícito é retratado, tanto em pesquisa acadêmica quanto em casos concretos, como envolvendo pelo menos três razões ou propósitos: um ajuste de responsabilidade moral, compensação de vítimas e dissuasão (prevenção de acidentes). A metodologia legal raciocina sobre esses propósitos caso a caso e tenta obter um equilíbrio apropriado. Mas o objetivo de realização simultânea dos três propósitos está se tornando cada vez mais difícil devido a mudanças no ambiente social e na periferia do direito. Como resultado, a responsabilidade civil em si está sob ataque e é considerada por algumas autoridades como de improvável sobrevivência a mais um século de desenvolvimento.

Do ponto de vista interno do direito de responsabilidade civil, o problema é triplo: conflitos entre os propósitos, ineficiência em alcançá-los e necessidade de coordenação com outras instituições sociais e jurídicas (e nenhum desses problemas pode ser resolvido dentro das restrições do núcleo da metodologia jurídica básica existente). Compensação e dissuasão competem entre si. A eficiência compensatória é alcançada ampliando a cobertura; a dissuasão, restringindo-a. A responsabilidade estrita amplia a compensação, mas interfere na dissuasão (pelo menos ostensivamente), eliminando o critério de falha.

Além disso, mesmo que a compensação e a dissuasão possam ser dissociadas, no direito há limites estritos no cumprimento de qualquer um desses propósitos. $A$ compensação é limitada pelo requisito de causalidade (atribuição de responsabilidade a réus identificáveis) e a impossibilidade correspondente de "seguro social" (distribuindo o custo de uma maneira fiscalmente racional para uma ampla base de contribuintes). A dissuasão é limitada pela inadequação dos julgamentos monetários como método de controle social dos acidentes. Visto de qualquer perspectiva (compensação ou dissuasão), o litígio parece ser um mecanismo administrativo absurdo. E o direito da responsabilidade civil considera cada vez mais difícil reconhecer ou ignorar instituições

19 A história que estou contando aqui é essencialmente uma versão abreviada de SUGARMAN, Stephen D. Doing Away with Tort Law. California Law Review, Berkeley, v. 73, n. 3, pp. 555-664, 1985, e conclusões tiradas de meus próprios ensinamentos sobre os materiais clássicos de Direito dos Seguros. Veja STEINER, Henry J. Moral Argument and Social Vision in the Courts: A Study of Tort Accident Law. Madison: University of Wisconsin Press, 1987. 
sociais e jurídicas relacionadas, projetadas para atingir os objetivos da política de maneira mais eficiente (especialmente seguros privados - responsabilidade e danos - e seguros sociais, como remuneração dos trabalhadores). A regra de origem colateral ${ }^{20^{*}}$, por exemplo, parece uma dupla compensação socialmente desnecessária; mas o seu oposto (reduzir os julgamentos sobre ilícitos pelo montante da compensação alternativa) põe em dúvida a necessidade de lei sobre responsabilidade por ato ilícito em primeiro lugar. Planos de mitigação de falhas ${ }^{21^{*}}$ começam a substituir a responsabilidade por ato ilícito em várias áreas (automóvel, acidentes nucleares etc.); e as autoridades pedem repetidamente a substituição do direito de responsabilidade por ilícito por um plano mais abrangente de compensação e dissuasão.

Como devemos explicar esse padrão da responsabilidade por ato ilícito em transição? Por dentro, o passo fatal parece ser o reconhecimento de objetivos consequenciais da política social (compensação e dissuasão). Depois que o direito da responsabilidade por ato ilícito deixou seu ponto indiscutível no ajuste da responsabilidade moral, uma crítica fundamental com base na ineficiência da política tornou-se quase inevitável. Do ponto de vista externo, talvez explicando a adoção de objetivos consequencialistas, a história parece ser de crescente complexidade social e demanda por desempenho aprimorado. Em uma sociedade industrial, o direito da responsabilidade por ato ilícito teve que processar milhões de transações, em um cenário com exigências gigantescas de compensação e questão sensível de sub e super-dissuasão (considere a gripe suína como um exemplo de super-dissuasão com base na incapacidade do sistema de responsabilização para tributar os beneficiários da vacinação; o problema de atribuir causalidade; e, possivelmente, danos socialmente irrealistas).

Enquanto isso, essa mesma complexidade social provocou uma série de instrumentos de política social mais adequados, incluindo seguro social e privado. A venerável instituição responsabilidade por ato ilícito encontrou-se cercada por uma série de instrumentos políticos mais amplos, mais eficientes, mais planejados e racionalizados, direcionados para o mesmo conjunto de problemas. Pode ser feita uma defesa respeitável da vitalidade contínua de um direito de responsabilidade por ato ilícito mais bem definido neste ambiente moderno..22 Mas a principal razão de sua sobrevivência parece ser uma defesa profissionalmente orientada (e não particularmente adaptativa) do status quo.

Antecipando a Parte $B$, e seguindo as pressões da complexidade social ainda mais na direção da reintegração legal, podemos ver que a colcha de retalhos de políticas sociais que substituem gradualmente o sistema de responsabilização por ato

20 "N.T. No original, "collateral source rule".

21 "N.T. No original "No-fault plans".

22 Ver abaixo, nota 33. 
ilícito está se tornando ela mesma obsoleta. Lacunas, sobreposições e desigualdades de indenizações são o resultado inevitável de sistemas legais e privados com cobertura limitada; e o desperdício social e econômico resultante parece menos barato. A prevenção de acidentes requer ajustes mais sensíveis, alguns envolvendo a participação ativa e a cooperação de possíveis infratores (por exemplo, responsabilidade da empresa). As políticas de interesse próprio e de interesse especial são um sério obstáculo à legislação necessária em ambas as frentes (por exemplo, posições privilegiadas em esquemas de compensação confortáveis, imunidade à dispendiosa prevenção de acidentes).

\section{DESINTEGRAÇÃO NO PENSAMENTO JURÍDICO E NA TEORIA DO ESTADO}

Nesta parte do artigo, quero contar a mesma história que na Parte A - núcleo, periferia, reintegração - de fora dos limites do pensamento jurídico, no campo do pensamento social chamado economia política. O pensamento jurídico e a economia política parecem não apenas partes semelhantes, mas fortemente relacionadas da mesma construção, uma incorporada na outra. A semelhança de estruturas não é a única razão para acreditar que as duas áreas de pensamento estão relacionadas. Há também vários pontos de convergência substantiva, em que as duas áreas de pensamento parecem estar dizendo a mesma coisa pela mesma razão. Como mostrado abaixo, o pensamento jurídico lida quase exclusivamente com as relações econômicas e usa as mesmas construções ideológicas para interpretá-las e moldá-las (libertarianismo, falha de mercado etc.).

Não obstante essa convergência, nem sempre conto a história de uma maneira que permita correspondência lógica ponto a ponto. Por exemplo, não mostro como cada tipo específico de reintegração no pensamento jurídico corresponde a um ponto específico no mapa da economia política. Em vez disso, tento estabelecer um conjunto paralelo de estruturas, descontinuidades e movimentos ideológicos. Embora não estritamente literal, acredito que a comparação ilumina, enriquece e acelera nossa compreensão do pensamento jurídico. Áreas sem vida do pensamento jurídico tornam-se vivas e significativas quando colocadas no contexto da economia política.

A estrutura bipolar da economia política, que corresponde ao núcleo e periferia do pensamento jurídico, é um núcleo da liberdade econômica e uma periferia da complexidade social, que sustento ser intrínseca a uma organização capitalista da economia. ${ }^{23}$ A próxima seção do artigo (B.I) descreve essa abordagem ou teoria da economia

23 A posição teórica deste artigo é uma mistura incomum de várias tradições diferentes. Com os marxistas, vejo contradições fundamentais no capitalismo; mas, com o CLS, nenhum materialismo, determinismo, guerra de classes ou teoria instrumental do Estado; e, como os principais críticos do capitalismo, vejo fortes tendências libertadoras nos dois principais projetos do capitalismo (como descrito na Parte B). Fortemente influenciado pela sociologia do direito, rejeito o instrumentalismo político desencarnado dessa escola. Também 
política, estabelecendo assim as bases para as seções subsequentes sobre a estrutura do direito. A Seção B.II descreve a estrutura bipolar do direito correspondente, incluindo tendências à reintegração nos aspectos periféricos da economia política, enfatizando a cooperação social. A Seção B.III discute as contradições (tensões) entre o núcleo e a periferia, que explicam melhor o senso de descontinuidade no direito e a dificuldade de realizar o projeto de cooperação social e reintegração jurídica.

\subsection{Os dois projetos do capitalismo: liberdade econômica e interde- pendência social}

O capitalismo pode ser considerado como envolvendo dois grandes projetos, ambos intrínsecos à sua existência como forma de organização social: liberdade econômica e interdependência social. A liberdade econômica é extremamente familiar porque corresponde à teoria do liberalismo clássico e é a principal característica da ideologia política contemporânea sobre o capitalismo. Para os formados em Direito, a liberdade econômica corresponde à estrutura facilitadora do mercado do currículo

coloquei a sociologia do direito dentro do pensamento jurídico, e não fora, onde ele se percebe. Sigo os neo-weberianos nas idéias de rematerialização e complexidade social, mas rejeito o tema evolucionista em favor da fragmentação e da contradição. Finalmente, este artigo é fortemente influenciado pela teoria da autopoiese, uma teoria dos sistemas vivos auto-organizados, incluindo a comunicação. A autopoiese se torna o veículo para preencher a lacuna entre pensamento e ação. No entanto, diferentemente dos proponentes de sistemas autopoiéticos estritamente fechados, vejo sistemas mistos e fragmentados com núcleos protegidos, periferias abertas e muitas contradições internas capazes de desconstrução. Um conjunto ilustrativo de referências correspondentes às influências acima é: JAMES O'CONNOR, James. The Fiscal Crisis of the State. New York: St. Martin's Press, 1973; OFFE, Claus. Disorganized Capitalism: Contemporary Transformations of Work and Politics. Cambridge: MIT Press, 1985; OFFE, Claus. Contradictions of the Welfare State. Cambridge: MIT Press, 1984; GORDON, Robert. Critical Legal Histories. Stanford Law Review, Stanford, v. 36, pp. 57-125, 1984; WHITE, G. Edward. From Realism to Critical Legal Studies: A Truncated Intellectual History. Southwestern Law Journal, Los Angeles, v. 40, n. 2, pp. 819-843, 1986; PIORE, Michael; SABEL, Charles. The Second Industrial Divide: Possibilities for Prosperity. New York: Basic Books, 1984; LUHMANN, Niklas. The Differentiation Of Society. New York: Columbia University Press, 1982; TEUBNER, Gunther. Substantive and Reflexive Elements in Modern Law. Law \& Society Review, New Jersey, v. 17, n. 2, pp. 239-286, 1983; TEUBNER, Gunther. Autopoiesis in Law and Society: A Rejoinder to Blankenburg. Law \& Society Review, New Jersey, v. 18, n. 2, pp. 291-301, 1984. $\mathrm{Na}$ forma narrativa, minha abordagem é mais ou menos assim. Comece com a proposição de que estrutura social, toda estrutura social, é uma percepção rotinizada de significado e sistemas de interação simbólica. Os sistemas são um tanto autônomos, possuindo sua própria lógica e códigos culturais que resistem ao discurso exógeno. Os sistemas nesse sentido incluem famílias, organizações, instituições, a economia (um sistema de códigos simbólicos baseados no preço), moda, direito. Mas os sistemas também estão ligados e conectados, compartilhando certas construções sociais comuns. É fato que as pessoas podem suportar sistemas internos e externos - sentir a estética da moda e analisá-la; raciocinar legalmente, bem como desconstruir esse raciocínio. E talvez a capacidade de permanecer dentro e fora dos sistemas, um sistema de sistemas de decodificação, seja ela própria um produto da complexidade social, surgindo naturalmente do encontro com múltiplos sistemas de significado. Ver HELLER, Thomas C. Structuralism and Critique. Stanford Law Review, Stanford, v. 36, n. 1/2, pp. 127-198, 1984. Isso não significa que a lei seja "o instrumento" do capitalismo. O direito faz parte do capitalismo; e o capitalismo é constituído por lei, tanto quanto seus outros sistemas constitutivos. Não há capitalismo puro e desnaturado orquestrando os sistemas culturais a partir de algum local central oculto. E, embora nossa cultura possa estar preocupada com coisas materiais, não há causação material (tudo é simbólico, até símbolos sobre as coisas). 
do primeiro ano, baseada, como é, em modelos de liberalismo clássico (propriedade, responsabilidade civil, contrato, em sua forma não adulterada, direito penal como proteção da propriedade; direito constitucional como uma exceção piegas). A liberdade econômica é intrínseca ao capitalismo porque o capitalismo envolve a delegação de autoridade aos proprietários que têm o direito de tomar decisões sobre políticas econômicas e sociais e reter lucros.

Mas o capitalismo também envolve um projeto intrínseco de interdependência social e complexidade emergindo dos subprodutos cooperativos de transações de mercado e atividade política coletiva concertada. Mercados produzem redes de produção, consumo, comércio e inovações interligadas. A atividade política coletiva gera organizações complexas de produção e marketing, além de planejamento econômico e social, jurídico e não jurídico. (Pense no design da economia de produção em massa, envolvendo uma organização característica do local de trabalho, um modelo de relações entre gestão e trabalho, controles complexos sobre mercados de massa, design de programas de bem-estar para manter a demanda. ${ }^{24} \mathrm{Em}$ escala global, pense no Fundo Monetário Internacional, seus clientes, constituintes e maquinações.)

Em um sentido geral, o projeto de complexidade e interdependência parece envolver duas tendências que se reforçam mutuamente: (1) O aumento da densidade da vida social (o fim de espaços vazios e o crescente desenvolvimento de recursos humanos e naturais). Para tornar a sociedade mais produtiva, o capitalismo construiu incansavelmente inúmeras vias de coordenação e comunicação. (2) Informações sofisticadas sobre interdependências. A mesma tecnologia necessária para criar mais produção também demonstra as interdependências de maneiras mais difíceis de obscurecer politicamente. Pense no papel da informação nos debates sobre chuva ácida, guerra e testes nucleares e tabagismo. Embora todos esses exemplos venham do conhecimento

24 HECLO, Hugh. Modern Social Politics in Britain and Sweden: From Relief to Income Maintenance. New Haven: Yale University Press, 1974: "Talvez a mudança mais fundamental dada como certa é o crescimento da política social moderna. Ocorrendo no período de três ou quatro gerações humanas, implica uma transformação que os escritores das décadas de 30 e 40 costumavam chamar de 'uma nova fase na história do homem'. Quase a única vez em que nosso bisavô entrou em contato direto com o estado foi quando ele postou uma carta ou encontrou um policial [...] Hoje, na maioria das nações industrializadas, o cidadão encontra muito do que ganha com o estado. Uma grande parte desse dinheiro vai para prever o seu futuro antes de qualquer questão que surge de sua incapacidade pessoal para ajudar a si mesmo. Se ele estiver doente ou se machucar, se envelhecer ou for incapaz de encontrar um emprego, se seu cônjuge tiver filhos ou morrer, se procurar moradia ou educação, é quase inevitável um envolvimento explícito ou implícito com uma política social do Estado [...] Enquanto a taxa da despesa total do governo nos países industrializados cresceu talvez 80 a 90 vezes em termos reais durante este período, a taxa de gastos com a política social tem, provavelmente, multiplicaram por 5000 a 6000 vezes [...]. Quando essas mudanças na provisão social por parte do governo são identificadas, elas geralmente adquirem o rótulo de estado de bem-estar coletivo [...] Neste estudo, prefiro usar o termo política social para designar intervenções estatais destinadas a afetar o jogo livre das forças de mercado no interesse do bem-estar dos cidadãos." (Ênfase no original). Também PIORE, Michael; PIORE, Michael; SABEL, Charles. The Second Industrial Divide: Possibilities for Prosperity. New York: Basic Books, 1984; JACOBS, Jane. Cities and the Wealth of Nations. New York: Random House, 1984; HANDLER, Alfred D. The Visible Hand: The Managerial Revolution in American Business. London: Harvard University Press, 1977. 
produzido pelas ciências físicas, os modelos de interdependência também exercem grande influência nas ciências sociais. Considere previsões econômicas, estimando os custos sociais da negligência infantil, terapia familiar e a ênfase do feminismo nas redes sociais e apoio social.

Devido ao aumento da complexidade social e da interdependência, as ações em uma esfera de atividade parecem produzir efeitos observáveis quase imediatos em várias outras áreas. A produção industrial cria chuva ácida que prejudica o comércio turístico de outras partes do estado, de outros estados ou de outros países. O bem-estar econômico dos países do terceiro mundo afeta o bem-estar econômico das economias avançadas. Os exercícios de guerra em El Salvador produzem refugiados de língua espanhola no Texas. Controles de aluguel afetam o suprimento de moradias. A tecnologia se desenvolve e é disseminada rapidamente.

\subsection{Impacto dos dois projetos sobre o Direito: efeitos separados}

Aqui se discutem os impactos distintos sobre a lei dos dois projetos do capitalismo na lei (a estrutura básica do núcleo e periferia). O efeito das contradições será considerado na próxima seção.

\subsubsection{O núcleo da liberdade econômica}

O impacto da liberdade econômica no direito é dinamismo econômico e hegemonia. Como o direito delegou tanto poder aos atores econômicos, ele também deve lidar com as consequências, profundas, generalizadas, rápidas e em constante mudança.

A primeira consequência do dinamismo econômico e da hegemonia (predominância na vida social) é simplesmente a substância ou o conteúdo do Direito. A maior parte do nosso Direito é economia política, uma vasta rede de disposições para facilitar transações de mercado, resolver conflitos e prevenir consequências danosas. Humanistas jurídicos, como eu, acabam experimentando uma revelação sobre o domínio dos negócios e da economia no direito. Praticamente todo o currículo da faculdade de direito se resume à produção e distribuição de riqueza. O direito da família se preocupa com os direitos de propriedade. O direito penal tem muito a ver com pobreza e propriedade (por exemplo, drogas). A assistência à infância e seus ferimentos associados, que se tornam os problemas de saúde mental de amanhã, passam a se concentrar no problema de atender às necessidades de dependência de crianças em um mundo de duas famílias assalariadas e monoparentais (e em um mundo de auto-preocupação mercantilizada). O direito eleitoral (the law of politics) se torna em grande parte uma questão de quais controles colocar sobre o poder da riqueza no processo eleitoral. Tão 
profunda é essa conexão entre negócios e direito, tão arraigada em nossa consciência, que é difícil imaginar outra maneira. Os negócios são os gigantes do bairro.

A segunda conseqüência é a velocidade e a diversidade das mudanças produzidas por decisões econômicas descontroladas. Responsabilidade por produtos, leis de imigração, proteção ambiental, regulamentação de bancos, segurança no emprego, impostos - todas essas áreas do direito e muitas outras refletem ajustes contínuos nas mudanças constantes provocadas pelos atores econômicos e nas demandas políticas resultantes por compensação.

\subsubsection{A periferia da interdependência social}

A conexão entre complexidade social e pensamento jurídico é multifacetada. Um efeito é uma expansão ampla da gama de aplicações do Direito. Um número cada vez maior de conflitos exige alguma forma de ajuste pelo menos temporariamente vinculativo e estável - portanto, uma tendência à juridificação generalizada. O aspecto da liberdade econômica do Direito é um sistema não-intrusivo de facilitação para o capitalismo laissez-faire, além de um sistema de regras firmemente consolidado para resolver disputas nos tribunais. É firme, elegante; e isso não adianta muito. Por causa da interdependência, o Direito está envolvido em tantas coisas que é razoável falar sobre a juridificação da sociedade (e de suas instituições subsidiárias - a juridificação da educação, negócios, etc.). Aparentemente, o Direito está tentando servir como o chamado mecanismo de orientação para resolver algumas das múltiplas interdependências da sociedade moderna, em áreas como proteção ambiental, ajustes macroeconômicos, prestação de serviços humanos, proteção ao consumidor e assim por diante. Ninguém que pensou que todo o Direito fosse descrito nos Comentários de Blackstone compreenderia criações modernistas como Simpson-Mazzoli, Gramm-Rudman ou a Lei da Educação para Todas as Crianças com Deficiência.

Mas a expansão do Direito não é simplesmente uma questão de proliferação de regras técnicas. Juntamente com a crescente gama de problemas e questões sociais, tem havido um crescimento paralelo de normas de justiça abrangentes, como proteção igual, devido processo legal e justiça administrativa. Isso não quer dizer que as normas de justiça transformam áreas inteiras da vida social. As normas são marginais e contestadas a cada passo do caminho. Mas eles também não podem ser descartados como insignificantes. No lado judicial, pense em desenvolvimentos como exceções ao direito de dispensa de empregado ${ }^{25^{*}}$, um tipo de segurança no trabalho feita enxertado judicialmente; ou direitos de devido processo legal no processo de imigração e nas

25 "N.T. No original está "exceptions to the contract at will". "At will" parece ser um instituto do direito do trabalho estadunidense equivalente à dispensa sem justa causa, ou, nesse caso, parece se referir ao direito de se dispensar imotivadamente. 
escolas; ou regulamentação judicial de contratos de seguro; e cada um deles tem contrapartidas legislativas e administrativas óbvias: regulamentação de pensões, códigos disciplinares, seguro social.

Um segundo efeito da interdependência no pensamento jurídico é um novo requisito de desempenho - as soluções jurídicas devem funcionar e isso tem outros dois efeitos. Mais importante, o Direito não pode se dar ao luxo de permanecer ideologicamente ignorante de seus efeitos. A orientação política, incluindo a jurisprudência sociológica, substitui o pensamento moralista. Além disso, para servir como parte de um processo flexível de solução de problemas, o Direito deve adquirir um alto grau de positivismo e politização. Positividade significa que o Direito pode ser projetado e redesenhado para atender às novas circunstâncias com novos ajustes. A política também ajuda o Direito a ser mais responsivo, porque a pressão pela resolução de disputas é sentida primeiro e rapidamente na esfera política.

Projetada ainda mais, a tendência para a complexidade social se afasta do positivismo e ruma à reintegração social e legal (incluindo uma nova forma de direito). A organização e a política social democrática pode ser vista como um facilitador necessário da interdependência social. As empresas e outros tipos de organizações aprendem que as antigas formas burocráticas e hierárquicas de autoridade são ineficientes e devem ser substituídas por um novo princípio de organização: participação e capacitação da equipe. ${ }^{26} \mathrm{~A}$ tendência também pode ser vista na análise de políticas. Indo além do comando e controle, da política de cima para baixo e até das formas mais sofisticadas de análise de implementação unidirecional, a política do governo deve descobrir meios de mobilizar a cooperação de organizações regulamentadas. Enquanto isso, uma classe média educada em todo o mundo, com expectativas de segurança, participação, dignidade e qualidade de vida, pode ser o motor do aumento da democracia política. A organização econômica global pode prenunciar a cooperação social em escala planetária.

Infelizmente, para aqueles que não conseguem ver evidências de uma vitória final dessas tendências benéficas, deve-se admitir que a realidade política em um dado momento também consiste em alguns grupos que tentam criar zonas de segurança e bem-estar à custa de outros; e que alguma juridificação decorre de inúmeras séries de direitos de propriedade projetados para criar fronteiras protegidas. Essa parte da história é apresentada na próxima seção, sobre contradições político-econômicas.

26 PETERS, Thomas J.; JR., Robert H. Waterman. In search of excellence: Lessons from America's best-run companies. New York: Harper \& Row, 1982; KANTER, Rosabeth M. The Change Masters - Innovation and Entrepreneurship in the American Corporation. New York: Simon Schuster, 1984. 


\subsection{Impacto das contradições no Direito}

Os dois projetos do capitalismo são mutuamente reforçadores e contraditórios. Os mercados exigem e produzem cooperação social, mas a liberdade a prejudica. A interdependência é cada vez mais uma condição do capitalismo, mas reduz a hegemonia dos proprietários. Em si mesma, a interdependência tem efeitos contraditórios: um processo acelerado de transferir problemas para os outros (ou, na linguagem econômica, externalizando-os), mas também resistência a ser descartado, com sofisticados controles sociais correspondentes. Essa transferência geralmente cria muitas reclamações de pessoas e organizações com alguma influência sobre quem a comete - daí um tipo diferente de conexão entre capitalismo, democracia e a classe média liberada. O restante desta seção discute os aspectos dessas contradições com mais detalhes. B.III.1 examina problemas de acesso a estruturas jurídicas complexas e fragmentadas produzidas por contradições sociais. B.Ill.2 estende a análise de acesso e associação à concepção do Estado de bem-estar social. A subseção final, B.Ill.3, é um exame dos problemas criados por contradições no sistema político per se (o que eu chamo "liberal democracia").

\subsubsection{Questões de acesso a benefícios coletivos}

A primeira reflexão das contradições sociais sobre o direito é o problema do acesso a benefícios coletivos. $\mathrm{O}$ direito responde à crescente complexidade desenvolvendo técnicas mais sofisticadas de planejamento social, culminando frequentemente na criação de estruturas administrativas projetadas para lidar com uma categoria de problema social em nome de uma classe de pessoas. Exemplos disso incluem manutenção de renda, seguro social, regulamentação de segurança, planejamento econômico e associação a organizações cujos membros são protegidos por vários direitos legais. $\mathrm{O}$ aspecto positivo desses programas é que eles protegem um grande número de pessoas de maneira razoavelmente eficiente, permitindo a coordenação com outros programas sociais (compare a eficiência da Previdência Social, por exemplo, com o seguro privado ou, especialmente, a responsabilidade civil, não obstante as objeções de Milton Friedman).

O problema de acesso vem da questão da associação. Quase todo programa social levanta questões de associação (entrada / saída) e estratificação interna. As questões de associação geralmente são óbvias, começando pelas questões de imigração que determinam a associação em países ricos, até o emprego em organizações estáveis, cobertura pelo seguro social e proteção pelas leis de segurança. A estratificação interna da proteção é mais sutil, mas também recebe muita atenção, por exemplo, o destino dos idosos com cortes de custos no seguro de saúde ou a cobertura prática para pessoas pobres sob o seguro de saúde administrado, como planos de saúde. 


\subsubsection{O desenho do Estado de bem-estar social}

Em grande escala, questões de planejamento e acesso, inclusão e exclusão podem ser vistas no desenho do Estado de bem-estar. Segundo pesquisas recentes, parece que as economias de mercado / bem-estar são mantidas juntas por algum tipo de design amplo e descoberto de forma incremental, como a economia de produção em massa descrita por Piore e Sabel. ${ }^{27}$ E é razoável acreditar que o design atual está em crise. A parceria entre a produção em massa e a economia keynesiana de bem-estar se baseia em excesso de capacidade, concorrência internacional improdutiva, o colapso do movimento trabalhista e uma ideologia popular, mas degenerada do liberalismo. A atual onda de filosofia conservadora parece representar uma repressão do lado coletivo do capitalismo, uma perda de memória sobre o papel construtivo do capital e o interesse próprio no Estado social. No momento, o programa de liberdade econômica tornou-se desequilibrado de sua contraparte coletiva. Conservadores (como David Stockman) agora na verdade, argumentam que praticamente todos os gastos do governo representam um subsídio para o setor improdutivo da sociedade, eliminando em um único golpe dogmático as finanças públicas sobre externalidades e a economia keynesiana sobre o interesse do capitalismo em manter a demanda entre trabalhadores e consumidores ociosos e mal pagos.

Esse momento histórico abre a oportunidade de criar, inventar, forjar novos padrões sociais e econômicos, um empreendimento no qual as bolsas de estudos desempenham um papel. Seguindo sugestões presentes em todas as linhas de pesquisa - economia institucional, teoria organizacional, feminismo - podemos assumir que o novo plano deve alcançar um grau mais alto de participação e associação do que o antigo. Maior produtividade exigirá maior cooperação (apropriação e entendimento local, incentivos superiores etc.). No entanto, o campo de batalha está repleto de conflitos e obstáculos. A nova tecnologia da informação, por exemplo, pode ser outro esforço do capital para aumentar a produtividade, isolando os trabalhadores e criando uma cooperação social unidirecional (hierárquica). ${ }^{28}$

\subsubsection{Democracia liberal}

As contradições entre os dois projetos do capitalismo também se refletem na ordem política desenvolvida no Ocidente para lidar com o domínio econômico - política democrática liberal e capitalismo do Estado de bem-estar social. ${ }^{29} \mathrm{~A}$ interdependência

27 PIORE, Michael; SABEL, Charles. The Second Industrial Divide: Possibilities for Prosperity. New York: Basic Books, 1984.

28 ROJAS, Fernando. Is Information Technology a Capitalist Tool for Further Subordinating Workers? Madison: Institute for Legal Studies - University of Wisconsin, 1987.

29 Resumindo, baseio-me no trabalho de Claus Offe, supra, nota 19; e faço referência ao meu próprio artigo, cujo rascunho foi apresentado na primeira conferência américo-germânica sobre direito reflexivo. Ver CLUNE, 
social pressiona o direito a ser mais sofisticado, funcional, adaptável e socialmente responsivo. Ele se ajusta pela diminuição do formalismo, maior abertura a ordens simbólicas concorrentes, técnicas aprimoradas de desconstrução, novas instituições reguladoras (negociação, novos instrumentos de política etc.).

Mas o princípio do liberalismo contradiz e mina a base para uma resposta mais ampla, mais coerente, estável e cooperativa ao domínio econômico. Essa erosão ocorre de quatro maneiras conectadas. Primeiro, o libertarianismo está preocupado com a proteção da liberdade econômica, com exclusão de políticas coletivas mais cooperativas e sofisticadas. Quase todo o desperdício e inadequação podem ser justificados para preservar as relações de poder políticas subjacentes. Segundo, os liberais no Estado de bem-estar social estão patrocinando enorme intervenção do governo sem qualquer justificativa filosófica ou teoria política coerente. O Estado se torna nada mais que o acúmulo de respostas ad hoc a crises econômicas e políticas. Terceiro, um vasto abismo se abre entre o filosofia política predominante do individualismo anacrônico do laissez-faire e a evidência esmagadora de intervenções governamentais maciças. O governo se torna uma série de decisões sem memória. Quarto, o liberalismo protege a liberdade econômica e resolve o paradoxo da ação governamental inexplicável através de uma degradação simbólica da política. A política se torna o perigoso inimigo imperialista de um setor privado produtivo, cativo de coletivos aquisitivos chamados "grupos de interesse especial".30

Mas a interdependência social também mina o liberalismo. O liberalismo ${ }^{31^{*}}$ organiza a política em termos de propriedade e direitos. As relações sociais são retratadas como consistindo de zonas de autonomia individual (propriedade) protegidas por poderosos recursos jurídicos (direitos). Aquilo que não for protegido ou que interfira na propriedade pode ser apropriado ou destruído, daí a busca de formas de externalizar custos, localizar novas fronteiras e transferir problemas para outra pessoa. O aumento da interdependência e da complexidade social torna o liberalismo irremediavelmente simplista e internamente contraditório. A proteção através da autonomia, imunidade e isolamento social se torna impossível. A proteção deve ser alcançada através da cooperação social e da solução funcional de problemas. O modelo de direitos começa a parecer um método ridículo de planejamento social, colocando os membros do coletivo uns contra os outros em uma série aleatória de concursos egoístas e desorganizados

\footnotetext{
William H. Unreasonableness and Alienation in the Continuing Relationships of Welfare State Bureaucracy: From Regulatory Complexity to Economic Democracy. Wisconsin Law Review, Madison. v. 1985, pp. 707-740, 1985.

30 Ver CLUNE, William H. Unreasonableness and Alienation in the Continuing Relationships of Welfare State Bureaucracy: From Regulatory Complexity to Economic Democracy. Wisconsin Law Review, Madison. v. 1985, pp. 707-740, 1985.

31 *NT. A expressão "liberalismo" nos Estados Unidos equivaleria ao "campo progressista" ou esquerda.
} 
que rompem os laços sociais e superam a quantidade total de recursos coletivos. ${ }^{32}$ Transações de mercado liberalizadas facilitam a construção de complexidade social, interdependência e cooperação; mas o libertarianismo impede a coletividade de fazer ajustes desejáveis para externalidades e inseguranças resultantes, ou alcançar cooperação positiva indisponível através dos mercados. E claramente, essas duas contra-tendências da interdependência social estão em guerra uma com a outra. O formalismo decrescente e o aumento da flexibilidade institucional parecem anômalos, ameaçadores e contraditórios ao mundo da propriedade e dos direitos. ("Flexível, você diz. Não me parece uma propriedade"). ${ }^{33}$

E assim, parece liberalismo antiquado, pois um modelo abrangente de ordem social está em um verdadeiro estado de crise (não estresse - crise). O impacto das influências fragmentadoras descritas nesta seção pode ser visto no comportamento dos grupos populistas radicais de direita que atualmente ${ }^{34^{*}}$ estão ganhando força nos Estados Unidos. ${ }^{35}$ Cada grupo, confuso com as ações inexplicáveis do governo e obcecado com a liberdade econômica, tem sua própria teoria excêntrica ou bizarra da autonomia pessoal absoluta e seu próprio tipo de paranoia populista sobre quem é responsável pela perda de autonomia. As demandas absolutas por autonomia são paradoxalmente acopladas a programas punitivos contra grupos inimigos. As pessoas ameaçam a violência contra funcionários do governo por serem solicitadas a pagar impostos e usar cintos de segurança, depois se viram e exigem que o governo marque as pessoas com Aids e execute dependentes químicos. Essas divisões extremas entre ações pessoais e coletivas são extensões populistas das contradições entre individualismo e altruísmo reconhecidas por Kennedy no Direito da Responsabilidade Civil e dos contratos. ${ }^{36}$

32 OLSEN, Frances. Statutory Rape: A Feminist Critique of Rights Analysis. Texas Law Review, Austin, v. 63, n. 3, pp. 387-432, 1984; WHITE, G. Edward. From Realism to Critical Legal Studies: A Truncated Intellectual History. Southwestern Law Journal, Los Angeles, v. 40, n. 2, pp. 819-843, 1986; SPARER, Edward V. Fundamental Human Rights, Legal Entitlements, and the Social Struggle: A Friendly Critique of the Critical Legal Studies Movement. Stanford Law Review, Stanford, v. 36, n. 1/2, pp. 509-574, 1984.

33 CRIBBET, John Edward. Concepts in Transition: The Search for a New Definition of Property. University of Illinois Law Review, Champaign, [s.n.], n. 1, pp. 1-42, 1986.

34 "O termo "atualmente" se refere aos anos 1990, quando o texto foi escrito.

35 Para informações adicionais sobre o conflito percebido entre liberdade e autoridade na cultura americana, consulte MACAULAY, Stewart. Images of law in everyday life: The lessons of school, entertainment and spectator sports. Madison: Institute for Legal Studies University of Wisconsin-Madison Law School, 1986.

36 KENNEDY, Duncan. The political significance of the structure of the law school curriculum. Seton Hall Law Review, Newark, v. 14, n. 1, pp. 1-16, 1983; KENNEDY, Duncan. Form and Substance in Private Law Adjudication. Harvard Law Review, Cambridge, v. 89, n. 8, pp. 1685-1778, 1976; KENNEDY, Duncan. The Structure of Blackstone's Commentaries. Buffalo Law Review, Buffalo, v. 28, n. 2, pp. 205-382, 1979. As pessoas comuns parecem sentir um pouco de dor, angústia e confusão ao se apegarem à idéia de propriedade como fonte de proteção e conexão social. Os "colarinhos azuis ", "democratas conservadores " que conheço em Chicago, identificam a intromissão do governo em suas pequenas posses como socialismo, isolando-se do planejamento social cooperativo, e, no entanto, encontram essas mesmas posses constantemente em risco das transações de mercado e do inevitável e aleatório gerenciamento de crises da sociedade. estado de bem-estar. Os laços étnicos que proporcionavam modelos de comunidade genuína são dissolvidos nos novos padrões de burocracia racional, 


\section{CONCLUSÃO: O DIREITO TRADICIONAL EM UMA NOVA CHAVE, CAMINHOS ANTIGOS EM UM NOVO CENÁRIO}

O tema da desintegração jurídica é parcialmente uma manifestação de ansiedade; e conferências e documentos sobre desintegração jurídica são eventos parcialmente escatológicos sobre o fim do mundo jurídico. Como uma pessoa de faculdade de direito, eu seria negligente se não incluísse pelo menos uma seção curta para responder a uma pergunta óbvia emergente de todas essas supostas tendências longe do núcleo tradicional - o direito tradicional está morto? Eu diria que a análise jurídica tradicional é bastante vital, mas seu papel mudou e se tornou mais eclético. Apenas ao ver o Direito tradicional no cenário em mudança é possível apreciar seus papéis positivos selecionados. (Às vezes, eu tendo a usar "positiva" em um modo auto conscientemente orientado à esquerda que pode ser facilmente convertido para as posições políticas do próprio leitor).

Em certo sentido, a maior parte da ação mudou para outro lugar. A análise de políticas substituiu a racionalidade moral como retórica dominante da formação de políticas. A finalidade jurídica separada da análise de políticas tende a ser um pouco vazia. Instituições jurídicas como tribunais e litígios são, na melhor das hipóteses, apenas alguns dentre vários possíveis instrumentos políticos e, na pior, um anacronismo irritante. A common law da facilitação do mercado não está na vanguarda do desenvolvimento social. Em muitos contextos, os advogados parecem não saber de nada útil e se especializam em obstrucionismo baseado em legalismos pitorescos ("o negligente deve pagar").

Mas essa imagem é válida apenas como uma generalização grosseira. Um olhar mais atento revela todos os tipos de projetos em andamento, alguns tradicionais, outros modernos. Um inventário muito pequeno desses projetos para dar uma noção da ideia é o seguinte: na categoria tradicional, as transações imobiliárias e as disputas comuns sobre propriedades são impossíveis de serem eliminadas em uma economia complexa, e algumas das disputas continuarão gerando demanda em litígios civis (e seus substitutos). O núcleo do método jurídico também não pode ser erradicado. Apesar da tendência em direção ao raciocínio prospectivo e consequencialista, há uma tendência igualmente forte em direção à finalidade legal. Uma situação social e econômica complexa realmente aumenta a demanda por estabilização de normas, ao mesmo tempo em que

consciência de mercadoria e classe social. Enquanto isso, o governo nacional eleito por suas ansiedades segue uma perigosa estratégia de minimalismo, preservando a quantidade máxima de liberdade econômica , permanecendo o mais próximo possível da fronteira da catástrofe social. Jogar esse tipo de galinha social requer bastante agilidade e nervosismo, características de personalidade com as quais nossa classe dominante empreendedora vem bem equipada. Mas a experiência social correspondente é estressante e assustadora. De muitas maneiras, a consciência social moderna é uma combinação bizarra de materialismo complacente (enfatizando os valores digestivos do consumo) e risco nauseante (emergindo da falta de cooperação social e reprimida abaixo da superfície plácida da vida consumista cotidiana). 
exige maior flexibilidade. Alguns assuntos devem ser considerados "como se" já estivessem decididos. À luz da necessidade de flexibilidade e da onipresença do raciocínio consequencialista, a reificação no direito (a "coisificação" (itness) associada à finalidade) muitas vezes parece artificial; mas não é "bobagem". ${ }^{37}$ Como já foi mencionado, a prevalência de esquemas jurídicos complexos com normas administradas burocraticamente representa um grau maior de finalidade (ou positivismo jurídico) em comparação com o common law de textura aberta.

Na categoria intermediária, o direito tem um forte papel a desempenhar nas disputas de associação (ou acesso) geradas por programas complexos de bem-estar social e planejamento econômico. O tipo mais simples de disputa consiste em identificar o tratamento de segunda classe e reclamar. Um projeto mais sutil é reconhecer obstáculos estruturados ao acesso, como a fragmentação do movimento trabalhista por meio de uma política de excepcionalismo. ${ }^{38} \mathrm{E}$, às vezes, a causa do acesso pode justificar o apoio a algumas instituições legais antiquadas. Um dos problemas do planejamento social moderno é a subversão dos interesses individuais e minoritários nos compromissos coletivos necessários para produzir um programa final. Por exemplo, os planos de saúde (Health Maintenance Organization-HMO) podem envolver um elemento de decepção do consumidor com publicidade de benefícios, que são, de fato, difíceis de obter. Ao mudar de um sistema baseado na demanda do consumidor para um sistema baseado em decisões de especialistas, mas também exigindo uma concorrência acirrada pelos clientes, há uma tentação de prometer muito e economizar dinheiro mais tarde. Em algum momento, esse comportamento pode cruzar a linha e se tornar algo que estaríamos dispostos a chamar de fraude ao consumidor. Nesse ponto, os direitos e soluções tradicionais para fraude podem ser bastante úteis. Remédios claros são especialmente úteis em um sistema burocrático complexo, onde ninguém se responsabiliza por consequências. O coletivismo diminui o alcance do individualismo, mas aumenta sua importância. ${ }^{39}$

37 WHITE, G. Edward. From Realism to Critical Legal Studies: A Truncated Intellectual History. Southwestern Law Journal, Los Angeles, v. 40, n. 2, pp. 819-843, 1986.

38 ROGERS, Joel. Divide and Conquer: The Legal Foundations of Postwar U.S. Labor Policy. In: JOERGES, Christian; TRUBEK, David M. (Orgs.). Critical Legal Thought: An American German Debate. Baden-Baden: Nomos, 1989. p. 213-235; STONE, Katherine Van Wezel. Re-Envisioning Labor Law: A Response to Professor Finkin. Maryland Law Review, Baltimore, v. 45, n. 4, pp. 978-1013, 1986.

39 Considere também a responsabilidade civil tradicional. A responsabilidade civil geralmente é um método grotescamente ineficiente e injusto de compensar as pessoas pelo custo dos acidentes e um exemplo perfeito de como o pensamento jurídico é substituído pela análise de políticas. Mas o remédio para delitos tem uma característica que pode justificar a preservação do sistema na forma modificada. Os esquemas de compensação administrados têm o problema de supercentralização, tanto na política legislativa que cria o esquema de compensação (suas regras de elegibilidade e danos, por exemplo) e política burocrática através da qual o esquema é administrado. Apenas descobrir quais regras se aplicam ou quem é responsável por alguma coisa pode ser impossível nas burocracias públicas bizantinas. Uma coisa boa da lei tradicional de delito é sua capacidade de superar a resistência burocrática por um processo, apoiado por poderosos direitos de descoberta, emergindo, por assim dizer, do nada. Os heróis do litígio sobre o amianto eram advogados de julgamentos, 
$\mathrm{Na}$ categoria avant-garde existem novos métodos de interpretação jurídica. Aqui, pensa-se no restabelecimento do raciocínio moral na interpretação legal e na análise de políticas, interpretação baseada nas realidades da implementação e no aumento do leque de possibilidades disponibilizadas por metodologias críticas.

Também na categoria avant-garde está o planejamento do bem-estar social por meio da escolha institucional. Uma maneira de reduzir a complexidade do planejamento social e o conflito entre liberdade e cooperação é por delegação, e não por receita detalhada. Em vez de regulamentação, a política social consiste em combinar as instituições com os objetivos da política, capacitando as organizações a assumir novas funções, e assim por diante. Por exemplo, a questão principal da política social em relação aos recém-nascidos gravemente enfermos pode ser considerada o local da tomada de decisão (médicos e famílias, conselhos de hospitais, tribunais, promotores etc.). ${ }^{40}$ Obviamente, o processo de escolha institucional em uma situação como essa não pode ser resolvido pelo método jurídico. Tudo depende da matéria da área (por exemplo, decisões médicas), da natureza das instituições (por exemplo, preconceitos dos profissionais da área médica), das restrições da situação de campo (como as decisões surgem) e do senso de ética. No entanto, mesmo que o treinamento jurídico não envolva um elemento de ética pragmática, ${ }^{41}$ a experiência jurídica no sentido estrito ainda é importante. Há um papel jurídico único em ajudar a formular os limites da escoIha institucional (por exemplo, "quem está gravemente doente"), estabelecendo procedimentos apropriados e projetando a interface com o restante do sistema jurídico (por exemplo, tribunais). Para que os advogados entendam essas questões, eles devem ficar imersos no assunto técnico e institucional. Tal prática híbrida está muito longe de uma ação judicial para recuperar um cavalo; mas ainda é direito.

\section{REFERÊNCIAS}

BARDACH, Eugene; KAGAN, Robert A. Going by the Book: The Problem of Regulatory Unreasonableness. Philadelphia: Temple University Press, 1982.

BOYLE, James. The Politics of Reason: Critical Legal Theory and Local Social Thought. University of Pennsylvania Law Review, Pennsylvania, v. 133, n. 4, p. 685-780, 1985.

porque só eles tinham incentivos e influência para romper a conspiração de pessoas de dentro da empresa. Devemos, portanto, proceder com muito cuidado com a renúncia a todas as proteções a burocracias públicas complexas e ter em mente a conveniência de remédios para litígios (se não o processo por delito privado tradicional, por exemplo, talvez algum tipo de ação do interveniente público). Em geral, a qualidade "imprevisível" dos recursos legais, que os torna dispositivos tão ruins para planejamento e programação, também os tornam bons candidatos a um tipo de democratização.

40 GOLDSTEIN, Joseph. Baby Doe: Problems and Legislative Proposals - Legislative Workshop. Arizona State Law Journal, Phoenix, pp. 601-692, 1984.

41 SCHNEYER, Ted. Moral Philosophy's Standard Misconception of Legal Ethics. Wisconsin Law Review, Madison, v. 1, pp. 1529-1572, 1984. 
CALABRESI, Guido. A Common Law for the Age of Statutes. Cambridge: Harvard University Press, 1982.

CLUNE, William H. A Political Model of Implementation and Implications of the Model for Public Policy, Research, and the Changing Roles of Law and Lawyers. lowa Law Review, lowa City, v. 69, p. 47-125, 1983.

CLUNE, William H. Institutional Choice as a Theoretical Framework for Research on Educational Policy. Educational Evaluation and Policy Analysis, [s.I.], v. 9, n. 2, p. 117-132, jun. 1987.

CLUNE, William H. Unreasonableness and Alienation in the Continuing Relationships of Welfare State Bureaucracy: From Regulatory Complexity to Economic Democracy. Wisconsin Law Review, Madison. v. 1985, p. 707-740, 1985.

CLUNE, William H.; PELT, Mark H. Van. A Political Method of Evaluating the Education for All Handicapped Children Act of 1975 and the Several Gaps of Gap Analysis. Law and Contemporary Problems, Durham, v. 48, n. 1, p. 7-62, dec./feb. 1985.

CRIBBET, John Edward. Concepts in Transition: The Search for a New Definition of Property. University of Illinois Law Review, Champaign, [s.n.], n. 1, p. 1-42, 1986.

GOLDSTEIN, Joseph. Baby Doe: Problems and Legislative Proposals - Legislative Workshop. Arizona State Law Journal, Phoenix, p. 601-692, 1984.

GORDON, Robert. Critical Legal Histories. Stanford Law Review, Stanford, v. 36, p. 57-125, 1984.

HANDLER, Alfred D. The Visible Hand: The Managerial Revolution in American Business. London: Harvard University Press, 1977.

HANDLER, Joel F. The Conditions of Discretion. [s.I.]: Russell Sage Foundation, 1986.

HECLO, Hugh. Modern Social Politics in Britain and Sweden: From Relief to Income Maintenance. New Haven: Yale University Press, 1974.

HELLER, Thomas C. Structuralism and Critique. Stanford Law Review, Stanford, v. 36, n. 1/2, p. 127-198, 1984.

JACOBS, Jane. Cities and the Wealth of Nations. New York: Random House, 1984.

JAMES O'CONNOR, James. The Fiscal Crisis of the State. New York: St. Martin's Press, 1973.

KANTER, Rosabeth M. The Change Masters - Innovation and Entrepreneurship in the American Corporation. New York: Simon Schuster, 1984.

KENNEDY, Duncan. Distributive and Paternalist Motives in Contract and Tort Law, with Special Reference to Compulsory Terms and Unequal Bargaining Power. Maryland Law Review, v. 41, n. 4, p. 563-658, 1982.

KENNEDY, Duncan. Form and Substance in Private Law Adjudication. Harvard Law Review, Cambridge, v. 89, n. 8, p. 1685-1778, 1976. 
KENNEDY, Duncan. The political significance of the structure of the law school curriculum. Seton Hall Law Review, Newark, v. 14, n. 1, p. 1-16, 1983.

KENNEDY, Duncan. The Structure of Blackstone's Commentaries. Buffalo Law Review, Buffalo, v. 28, n. 2, p. 205-382, 1979.

KOMESAR, Neil K. Taking Institutions Seriously: Introduction to a Strategy for Constitutional Analysis. The University of Chicago Law Review, Chicago, v. 51, n. 2, p. 366-446, 1984.

LUHMANN, Niklas. The Differentiation Of Society. New York: Columbia University Press, 1982.

MACAULAY, Stewart. Images of law in everyday life: The lessons of school, entertainment and spectator sports. Madison: Institute for Legal Studies University of Wisconsin-Madison Law School, 1986.

MASHAW, Jerry L. Positive Theory and Public Law. In: Rosenthal Lectures. [s.I.]: palestra proferida na Northwestern University Law School, arquivo do autor, fev. 1986.

MICHELMAN, Frank I. In Pursuit of Constitutional Welfare Rights: One View of Rawls' Theory of Justice. University of Pennsylvania Law Review, Pennsylvania, v. 121, n. 5, p. 962-1019, 1973.

MICHELMAN, Frank I. On Protecting the Poor Through the Fourteenth Amendment. Harvard Law Review, Cambridge, v. 1, n. 1, p. 6-59, 1969.

OFFE, Claus. Contradictions of the Welfare State. Cambridge: MIT Press, 1984.

OFFE, Claus. Disorganized Capitalism: Contemporary Transformations of Work and Politics. Cambridge: MIT Press, 1985.

OLSEN, Frances. Statutory Rape: A Feminist Critique of Rights Analysis. Texas Law Review, Austin, v. 63, n. 3, p. 387-432, 1984.

PALAY, Thomas M. Comparative Institutional Economics: The Governance of Rail Freight Contracting. The Journal of Legal Studies, Chicago, v. 13, n. 2, p. 265-287, 1984.

PELLER, Gary; ACKERMAN, Bruce. The Politics of Reconstruction. Harvard Law Review, Cambridge, v. 98, n. 4, p. 863-881, 1985.

PETERS, Thomas J.; JR., Robert H. Waterman. In search of excellence: Lessons from America's bestrun companies. New York: Harper \& Row, 1982.

PIORE, Michael; SABEL, Charles. The Second Industrial Divide: Possibilities for Prosperity. New York: Basic Books, 1984.

POSNER, Richard. Statutory Interpretation in the Classroom and in the Courtroom. University of Chicago Law Review, Chicago, v. 50, p. 800-822, 1983.

ROGERS, Joel. Divide and Conquer: The Legal Foundations of Postwar U.S. Labor Policy. In: JOERGES, Christian; TRUBEK, David M. (Orgs.). Critical Legal Thought: An American German Debate. Baden-Baden: Nomos, 1989. 
ROJAS, Fernando. Is Information Technology a Capitalist Tool for Further Subordinating Workers? Madison: Institute for Legal Studies - University of Wisconsin, 1987.

SCHLEGEL, John H. American Legal Theory and American Legal Education: A Snake Swallowing its Tail? In:TRUBEK, D.; JOERGES, C. (Orgs.). Critical Legal Thought: An American-German Debate. Baden-Baden: Nomos, 1989.

SCHNEYER, Ted. Moral Philosophy's Standard Misconception of Legal Ethics. Wisconsin Law Review, Madison, v. 1, p. 1529-1572, 1984.

SIMON, William H. Rights and Redistribution in the Welfare System. Stanford Law Review, Stanford, v. 38, n. 6, p. 1431-1516, 1986.

SPARER, Edward V. Fundamental Human Rights, Legal Entitlements, and the Social Struggle: A Friendly Critique of the Critical Legal Studies Movement. Stanford Law Review, Stanford, v. 36, n. 1/2, p. 509-574, 1984.

STEINER, Henry J. Moral Argument and Social Vision in the Courts: A Study of Tort Accident Law. Madison: University of Wisconsin Press, 1987.

STONE, Katherine Van Wezel. Re-Envisioning Labor Law: A Response to Professor Finkin. Maryland Law Review, Baltimore, v. 45, n. 4, p. 978-1013, 1986.

SUGARMAN, Stephen D. Doing Away with Tort Law. California Law Review, Berkeley, v. 73, n. 3, p. 555-664, 1985.

TAYLOR, Serge. Making Bureaucracies Think: The Environmental Impact Statement Strategy of Administrative Reform. Stanford: Stanford University Press, 1984.

TEUBNER, Gunther. Autopoiesis in Law and Society: A Rejoinder to Blankenburg. Law \& Society Review, New Jersey, v. 18, n. 2, p. 291-301, 1984.

TEUBNER, Gunther. Substantive and Reflexive Elements in Modern Law. Law \& Society Review, New Jersey, v. 17, n. 2, p. 239-286, 1983.

WHITE, G. Edward. From Realism to Critical Legal Studies: A Truncated Intellectual History. Southwestern Law Journal, Los Angeles, v. 40, n. 2, p. 819-843, 1986. 